\title{
Rapidly progressive dementia and intractable diarrhea: a teaching case report and a systematic review of cognitive impairment in Whipple's disease
}

\author{
Arianna Manini ${ }^{1} \cdot$ Giacomo Querzola $^{1} \cdot$ Carlo Lovati $^{2} \cdot$ Leonardo Pantoni $^{1}$ (D)
}

Received: 11 November 2021 / Accepted: 22 December 2021 / Published online: 3 January 2022

(c) Fondazione Società Italiana di Neurologia 2022

\begin{abstract}
Objective Whipple's disease (WD) is a systemic, chronic, relapsing disease caused by Tropheryma whipplei, which can mimic signs and symptoms of various clinical entities. Typical manifestations are represented by gastrointestinal and systemic symptoms, among which neurological ones are frequent. We present the case of a patient with WD and rapidly progressive cognitive impairment and a review of literature aimed to report epidemiological, clinical, neuroimaging, and laboratory findings of cognitive impairment associated with WD.

Methods A systematic review of medical literature published until November 22, 2020, was performed. Full-text, peerreviewed case reports and series in English language presenting patients with WD and cognitive impairment were included. Data concerning demographic, clinical, neuroimaging, and laboratory characteristics were collected and synthesized qualitatively.

Results The patient was a 54-year-old male who developed rapidly progressive dementia, fluctuating arousal disturbances, and supranuclear ophthalmoparesis associated with chronic diarrhea and fever spikes. T. whipplei was detected in the cerebrospinal fluid, and appropriate antimicrobial therapy was given with progressive clinical benefit. The systematic review of 114 case reports/series identified 147 patients with WD and cognitive impairment; this latter was rarely isolated. Neurological symptoms associated with cognitive decline were psychiatric disturbances, supranuclear ophthalmoplegia, hypothalamic involvement, and consciousness disorders. Brain imaging and cerebrospinal fluid findings were heterogeneous and nonspecific.

Conclusions Cognitive impairment represents one of the most common neurological features associated with WD. The clinical suspicion of this disease in patients with rapidly progressive dementia is crucial to guide diagnostic strategies and proper antimicrobial therapy, which may revert the clinical deterioration.
\end{abstract}

Keywords Whipple's disease $\cdot$ Tropheryma whipplei $\cdot$ Dementia $\cdot$ Cognitive impairment $\cdot$ Central nervous system

Arianna Manini and Giacomo Querzola equally contributed to this work

Leonardo Pantoni

leonardo.pantoni@unimi.it

1 Stroke and Dementia Lab, "Luigi Sacco" Department of Biomedical and Clinical Sciences, University of Milan, Via Giovanni Battista Grassi 74, 20157 Milan, Italy

2 Neurology Unit, "Luigi Sacco" University Hospital, Milan, Italy

\section{Introduction}

The first description of Whipple's disease (WD), a rare multi-systemic chronic illness caused by Tropheryma whipplei [1], dates back to 1895 [2]. In 1907, George Hoyt Whipple described a 36-year-old missionary with malabsorptive syndrome due to chronic unexplained diarrhea associated with migratory polyarthritis, cough, and mesenteric lymphadenopathy [3]. Since then, our knowledge of the pathogenic mechanisms and clinical manifestations of WD has grown, improving our ability of diagnosis and treatment. Nevertheless, different immunopathogenic aspects of the disease remain unclear. Most infected individuals do not develop symptomatic infection, protected by humoral and 
cellular immunity [4]. Therefore, detecting T. whipplei in tissues and biological fluids of asymptomatic carriers is not rare [5]. Typical and atypical presentations appear only in a few patients who show genetic predisposition and rarely immune deficits [6, 7]. Classical manifestations are represented by gastrointestinal symptoms, including diarrhea, weight loss, abdominal pain, nausea and vomit, and systemic features, such as fatigue, migratory arthralgias/ arthritis, fever of unknown origin, lymphadenopathy, and skin alterations [8]. Other symptoms are due to localized forms of T. whipplei infection, including the neurological ones. Nervous system involvement produces a broad range of signs and symptoms, whose the most typical is the classic triad of dementia, supranuclear ophthalmoplegia, and myoclonus [9].

Here, we report the case of a patient with WD and progressive cognitive decline and a literature review aimed to clarify epidemiological, clinical, neuroimaging, and laboratory findings of WD associated with dementia.

\section{Material and methods}

\section{Systematic literature review}

Two authors (A.M. and G.Q.) performed a systematic review of medical literature by searching two comprehensive medical databases, namely PubMed and Embase, from inception to November 22, 2020. The search query employed was "(whipple disease OR tropheryma whipplei OR tropheryma whippelii) AND (dementia OR central nervous system OR cognitive)." Full-text, peer-reviewed case reports and case series published in English language presenting patients with WD and cognitive impairment were included. All the abstracts were screened independently by the two authors to select full-text articles to be included in the analysis. In case of disagreement, relevant articles were re-reviewed until consensus was reached. The complete list of publications included in our systematic review is available in Supplementary Table 1. Data of eligible studies were collected, reported in a dedicated database, and combined, including age at onset and gender of patients; neurological and nonneurological clinical features; neuroimaging features; type of central nervous system (CNS) WD diagnosis (definite or possible) according to Louis et al.'s criteria [10]; and results of CSF examination. Data were qualitatively synthesized, and descriptive analyses were performed using open-source software "Jamovi," version 1.6 (Sidney, Australia).

Case reports and series were included in the systematic review if the authors used one of the following expressions to describe patient's clinical condition: "cognitive impairment," "cognitive decline," "cognitive changes," "cognitive alterations," "cognitive abnormalities," "cognitive disorder," "cognitive defects," "cognitive deterioration," "cognitive deficits," "cognitive disturbances," "cognitive dysfunction," "cognitive symptoms," "cognitive complaints," "cognitive slowness," "cognitive sequelae," "neurocognitive features," "neurocognitive symptoms," "deterioration in cognition," "reduced cognition," "memory loss," "memory impairment," "decreased memory," "problems with memory," "memory lapses," "memory disturbances," "memory difficulties," "memory disorder," "poor memory," "memory deficits," "memory alterations," "amnesic syndrome," "dementia," "demented," "dementing illness," and "demential syndrome." When the authors did not report any of the previous terms, but described an acquired syndrome consisting of a loss of several separable but overlapping intellectual abilities that was significant enough to interfere with independent, daily occupational/domestic/social functioning, then the case was included in the analysis.

Other neurological and non-neurological features associated with cognitive deficits were also searched for in the publications. Considering other associated neurological features, these were classified in main categories (Supplementary Table 2).

After the literature search, we applied the Louis et al.'s criteria [10] for CNS WD for each of the selected cases. According to Louis et al.'s criteria [10], CNS WD is defined as "possible" when at least one out of four systemic symptoms (fever of unknown origin; gastrointestinal symptoms such as steatorrhea, chronic diarrhea, abdominal distension, or pain; chronic migratory arthralgias or polyarthralgias; unexplained lymphadenopathy, night sweats, or malaise), not due to another known etiology, is associated with at least one out of four neurological signs (supranuclear vertical gaze palsy; rhythmic myoclonus; dementia with psychiatric symptoms; hypothalamic manifestations), not due to another known etiology. CNS WD is otherwise "definite" if at least one of the following criteria is fulfilled: presence of oculomasticatory myorhythmia or oculo-facial skeletal myorhythmia; positive tissue biopsy (either periodic acid-Schiff (PAS) positive or bacteria seen on electron microscopy); and positive polymerase chain reaction (PCR) analysis. If histological or PCR analysis is not performed on CNS tissue, then the patient must also have neurological signs. If histological or PCR analysis is performed on CNS tissue, then the patient does not need to have neurological signs.

\section{Results}

\section{Case report}

The patient was a 54-year-old Caucasian male, professional musicist. Informed consent was given by the patient for the case report publication. 
He had a history of moderate chronic renal failure due to autoimmune membrane-proliferative glomerulonephritis (MPGN), associated with thrombocytopenia, cryoglobulinemia, and reduction in C3 and C4 fractions. Since the diagnosis in 2013, he had been treated with corticosteroids and immunosuppressive drugs, including cyclophosphamide and rituximab. The remaining history was remarkable only for atrial flutter, previously treated with oral anticoagulant drugs, benign prostatic hypertrophy, and major depressive disorder.

In February 2019, almost 1 month after a 10-day tour in China, the patient developed elevated fever, macrohematuria, and diarrhea which led to dehydration and acute chronic renal failure (ACRF). The patient was suspected to have a MPGN relapse, so that renal biopsy was performed, confirming MPGN with hyaline degeneration in about half of the glomeruli. He received treatment with intravenous steroid bolus (methylprednisolone $1 \mathrm{~g}$ for 3 days), followed by oral prednisone $50 \mathrm{mg}$ daily and two intravenous infusions of rituximab. Renal function partially improved and macrohematuria disappeared, whereas diarrhea persisted. Metronidazole and piperacillin/tazobactam were administered because of infectious suspicion, with no clinical benefit. Steroid doses were progressively reduced and mycophenolate mofetil was introduced as maintenance immunosuppressive treatment.

In March 2019, after a traumatic brain injury due to orthostatic syncope, he developed a subarachnoid hemorrhage which was complicated by vasospasm leading to a subcortical right fronto-temporo-parietal ischemic infarct (Fig. 1a-b) causing left hemiparesis and lower left quadrantanopia. The patient underwent rehabilitation, which ensured a good motor recovery, so that the patient could play the violin only with a slight hindrance of the left hand.

In July 2019, the persistent diarrhea led to a second admission to hospital for ACRF. Tests for Clostridium difficile detection (glutamate dehydrogenase assay and toxin A/B detection by enzyme-linked immunosorbent assay (ELISA)) and parasitological and stool tests were negative. Colonoscopy displayed hyperemia of the mucous membrane
Fig. 1 Patient brain imaging performed at different times during disease progression. $\mathbf{a}-\mathbf{b}$ Brain MRI (axial T1-weighted and T2-weighted images, respectively) performed in October 2019 showing diffuse cortical atrophy, lateral ventricles dilatation, more prominent on the right, and an area of hypointensity (a) and hyperintensity (b) in the location of the previous ischemic stroke. $\mathbf{c}-\mathbf{d}$ Brain MRI (axial FLAIR and T2-weighted images, respectively), performed in October 2020 , unvaried compared to the previous one
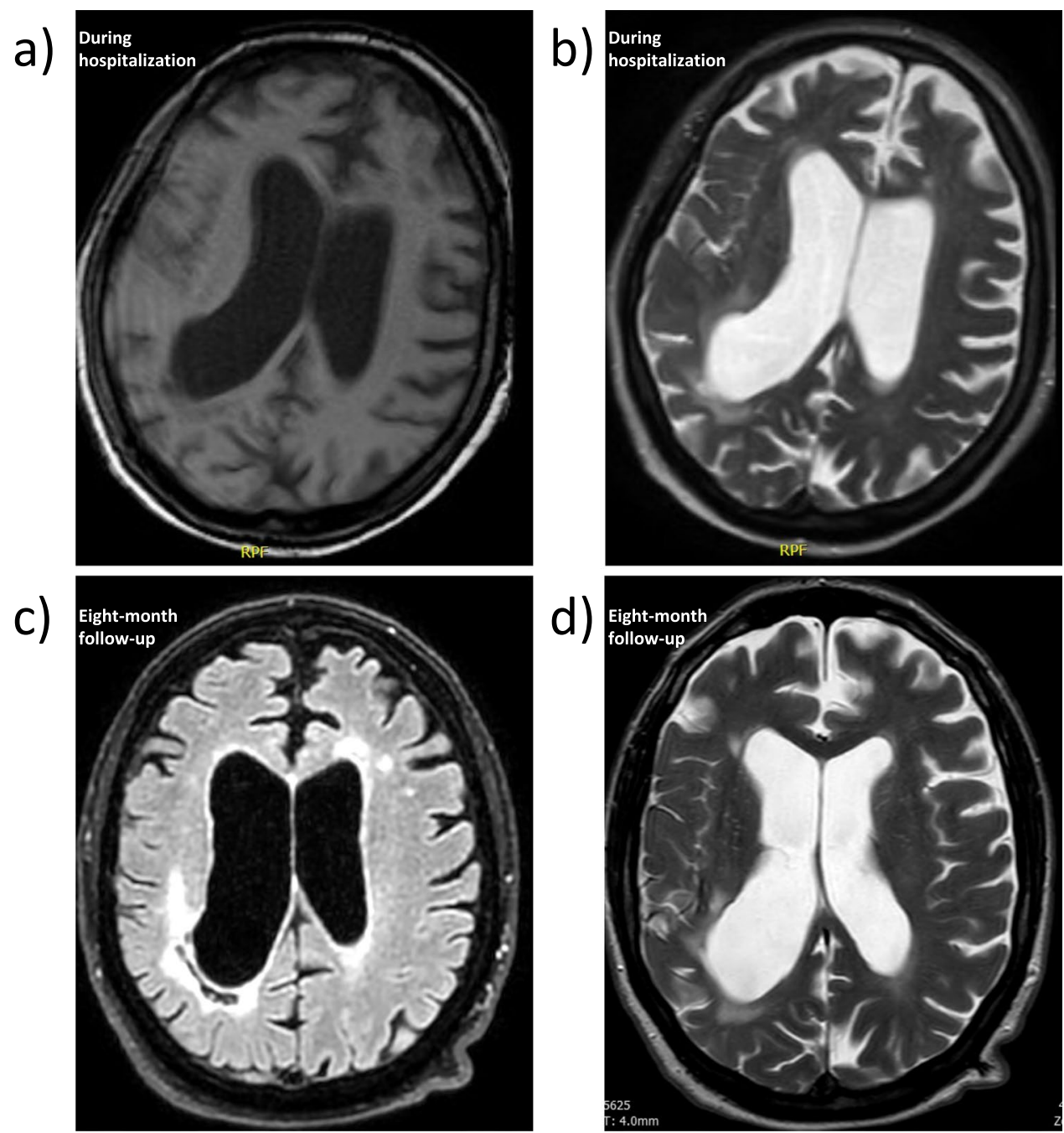
and erosions in the first $5 \mathrm{~cm}$ of the rectal mucosa. The pathological examination showed hyperplasia of glandular epithelium, edema of the lamina propria, exudative inflammation, with increase in the number of lymphocytes and plasma cells, and micro-abscesses in descending colon. The physicians hypothesized that diarrhea and pathological alterations were secondary to iatrogenic damage. As a consequence, it was decided to interrupt mycophenolate mofetil and to start mesalazine suppositories, which were replaced by beclomethasone dipropionate in August 2019 because of persisting diarrhea.

Soon after that, the patient began complaining of difficulties in concentration, especially concerning reading skills. By the end of September, a third ACRF secondary to persistent diarrhea led to admission to the Gastroenterology Unit. The use of cholestyramine partially improved diarrhea. Proctoscopy was normal, while small intestine ultrasonography revealed wall thickening of the last small bowel loop and of descending and sigmoid colon. Digestive endoscopy showed granular aspect of intestinal lining and lymphangiectasis of intestinal villi. The research of Helicobacter pylori and Isospora belli did not detect any microorganisms. A wide spectrum screening for infectious diseases was negative, including stool test for Giardia species, Entamoeba histolytica, and Cryptosporidium species and serology for adenovirus, rotavirus, hepatitis $\mathrm{B}$ and $\mathrm{C}$ viruses, and HIV $1 / 2$. Urinary 5 -hydroxyindoleacetic acid was normal, thus excluding the presence of neuroendocrine tumors. Fecal calprotectin was remarkably increased $(1304 \mu \mathrm{g} / \mathrm{g}$; normal value: $<50 \mu \mathrm{g} / \mathrm{g}$ ). No altered findings were detected by an autoimmune panel (antinuclear antibodies (ANA), extractable nuclear antigens antibodies (ENA), anti-mitochondrial antibodies (AMA), anti-alpha-smooth muscle actin antibodies (ASMA), anti-neutrophil cytoplasmic antibodies (ANCA), thyrotropin receptor antibodies (TRAB), thyroglobulin antibodies ( $\mathrm{TgAb}$ ), anti-transglutaminase antibodies (ATA), anti-gliadin antibodies (AGA), immunoglobulin $\mathrm{G}(\mathrm{IgG})$ ). The patient was concerned about the possible repercussions of iodinated contrast on the kidney condition and refused an enhanced computerized tomography (CT) of thorax and abdomen, proposed to exclude a possible paraneoplastic genesis of disturbances. Blood tests revealed $\mathrm{IgG}$ antibodies deficit. A reduced number of lymphocytes $\mathrm{T}$ $\mathrm{CD} 3+$ (both $\mathrm{CD} 4+$ and $\mathrm{CD} 8+$ ) and B CD19 + was detected at cytofluorimetry and an ensuing prophylactic therapy with cotrimoxazole on alternate days was initiated.

During hospitalization, he developed intermittent fever and an increase of inflammatory markers. Blood cultures and DNA amplification for Epstein-Barr virus (EBV), cytomegalovirus (CMV), varicella zoster virus (VZV), and herpes simplex virus (HSV) 1 and 2 were negative. After the employment of piperacillin/tazobactam, inflammatory markers gradually decreased.
Over about 10 days, the patient underwent a dramatic cognitive deterioration (i.e., he rapidly lost the possibility to speak and write a correct message on the cellular phone with a progressive disruption of grammatical and lexical structure of verbal functions; he was completely disoriented in time and space, and he was not any longer able to interact with health workers or family members). Considering the presence of chronic diarrhea and progressive cognitive impairment, an infective or inflammatory involvement of CNS, with the same origin of the gastrointestinal problem, was hypothesized, and the patient was transferred to the Neurology Unit. On admission, neurological examination revealed fluctuating arousal disturbances, attention deficits with difficulty in obeying motor orders, hypophonia, and echolalia. Eye movement examination displayed spontaneous nystagmus in primary gaze and more sustained in up and right-gaze, and bilateral limitation of ocular motility in horizontal gaze, which evolved in 2 days into ophthalmoparesis in all directions of gaze. Apparently as a worsening of the consequences of the previous ischemic stroke, the patient showed left hemiparesis, increased spastic tone of the left arm (in contrast with the reduced tone of the other three limbs), left Babinski sign, and extinction of left stimulus on double simultaneous stimulation. Blood tests showed normal level of leukocytes (6180 leukocytes/ $\mu \mathrm{L}$; normal values: 4190-9350 leukocytes/ $\mu \mathrm{L}$ ), high C-reactive protein levels $(132.6 \mathrm{mg} / \mathrm{L}$; normal values: $<10.0 \mathrm{mg} / \mathrm{L})$, normocytic $(90.5$ fL; normal values: $35-50 \mathrm{~g} / \mathrm{L})$ anemia $(8.4 \mathrm{~g} / \mathrm{dL}$; normal values: $14.2-17.2 \mathrm{~g} / \mathrm{dL})$, and hypoalbuminemia $(28 \mathrm{~g} / \mathrm{L}$; normal values: $35-50 \mathrm{~g} / \mathrm{L}$ ).

At this point, main differential diagnoses included infectious, autoimmune, deficiency, and genetic diseases (Table 1). Supplementation with thiamine did not produce clinical benefits. The absence of characteristic dermatitis consisting of symmetrical erythema in sun-exposed skin made the hypothesis of pellagra unlikely. Prion disease associated with diarrhea and neuropathy appeared doubtful due to the absence of typical autonomic failure and clinical signs of sensory polyneuropathy. The hypotheses of genetic diseases were rejected due to the rapid progression of symptoms and to the absence of clinical hallmarks (i.e., cobalamin $\mathrm{C}$ deficiency and acrodermatitis enteropathica-like; cerebrotendinous xanthomatosis and tendon xanthomas; transthyretin amyloidosis and autonomic dysfunction, cardiac involvement, carpal tunnel syndrome). A subtype of transthyretin amyloidosis called oculoleptomeningeal amyloidosis, although manifesting with neurological and neuropsychiatric symptoms such as dementia, does not produce the typical gastrointestinal picture. The hypothesis of complicated celiac disease did not fit with the absence of autoantibodies and of pathological hallmarks at duodenal biopsies. WD and anti-dipeptidyl-peptidase-like protein (DPPX) 6, although rare entities, could not be ruled out. 


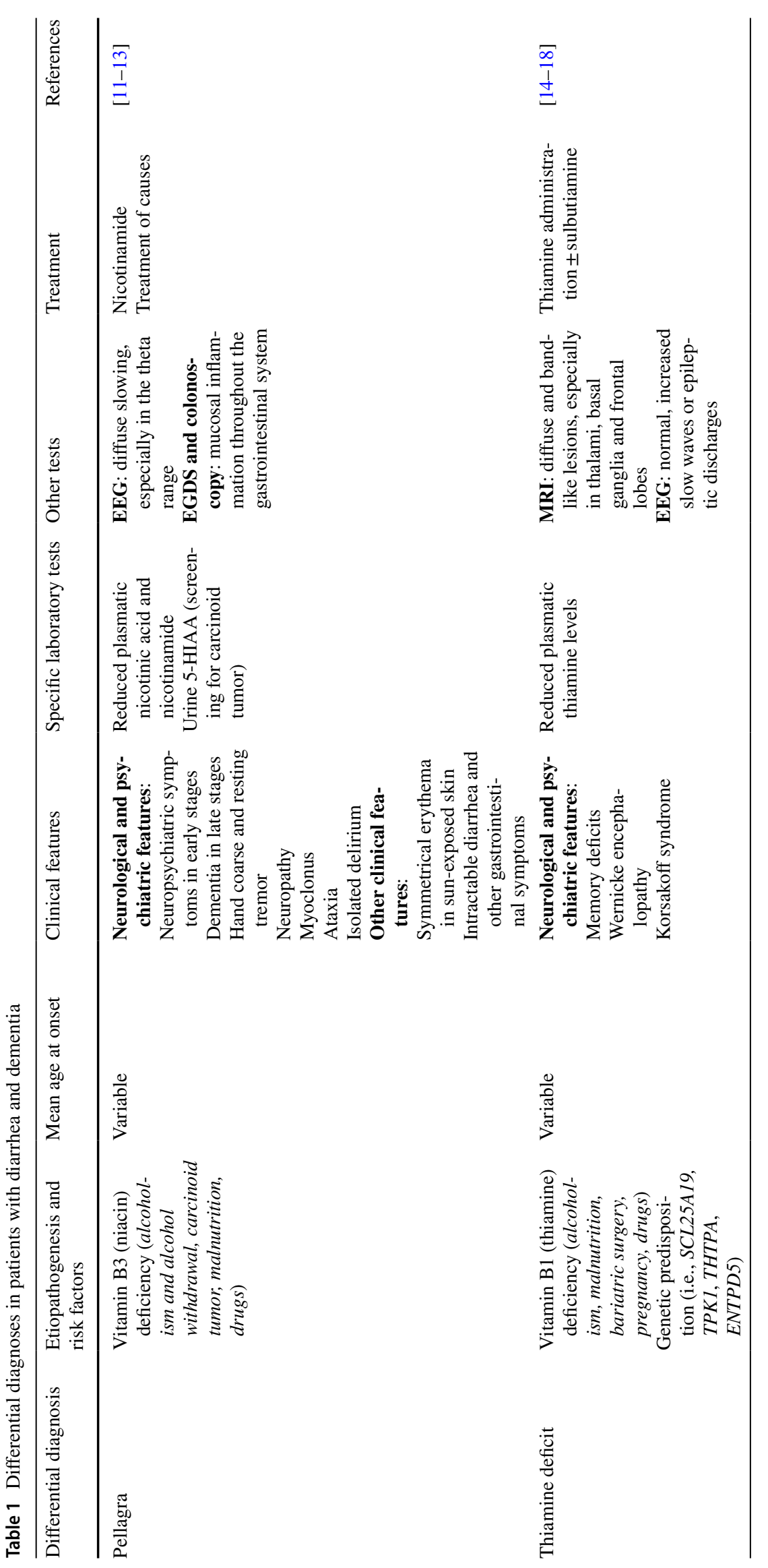




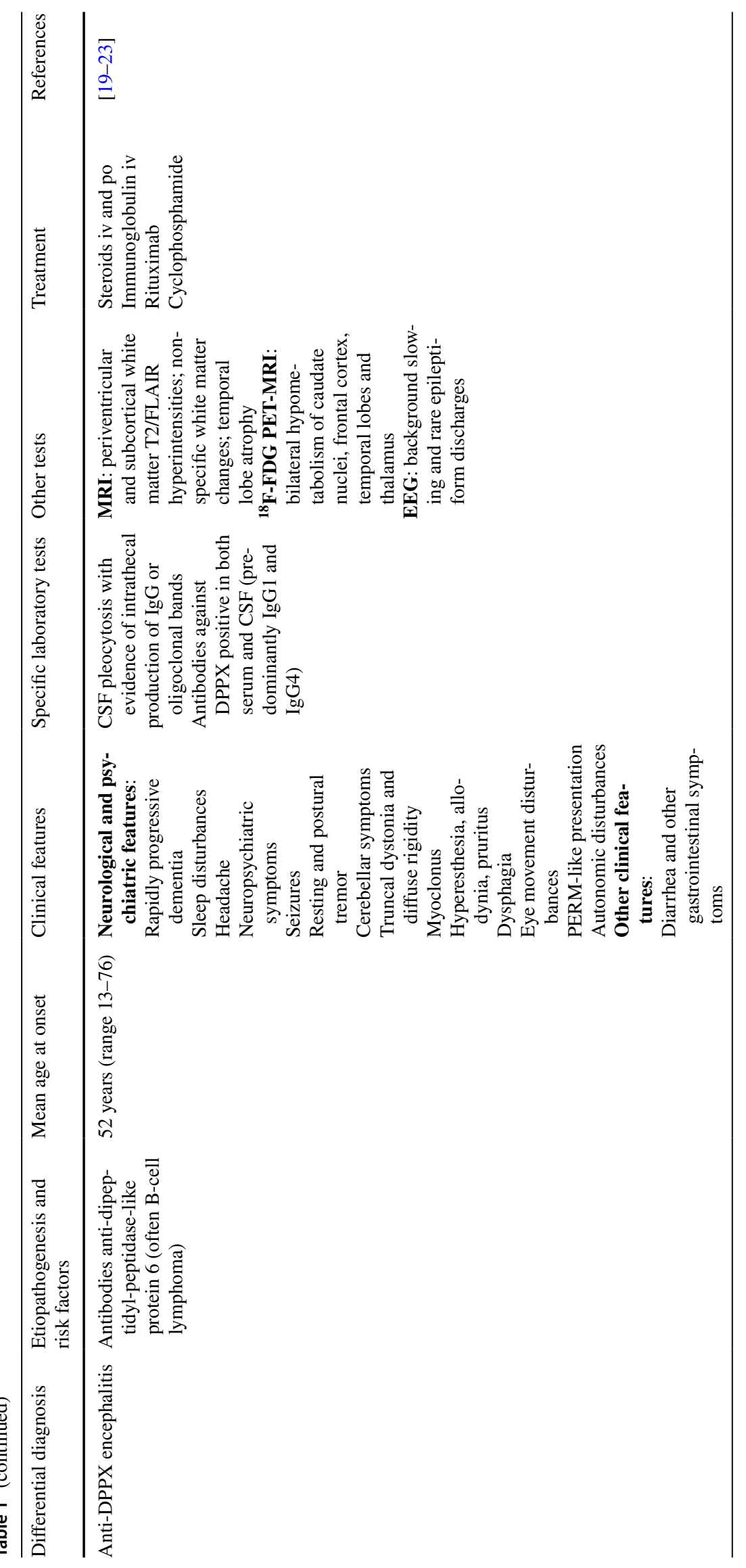




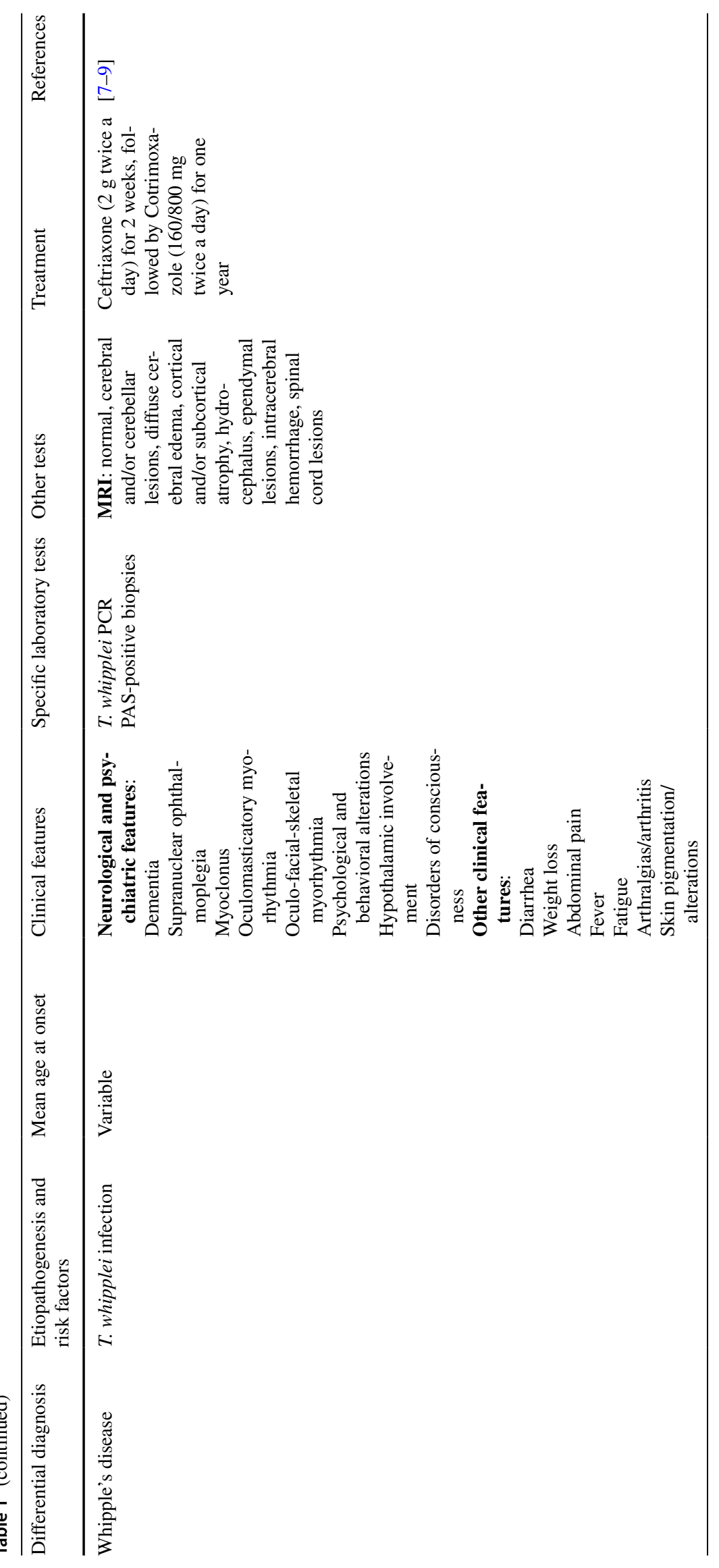




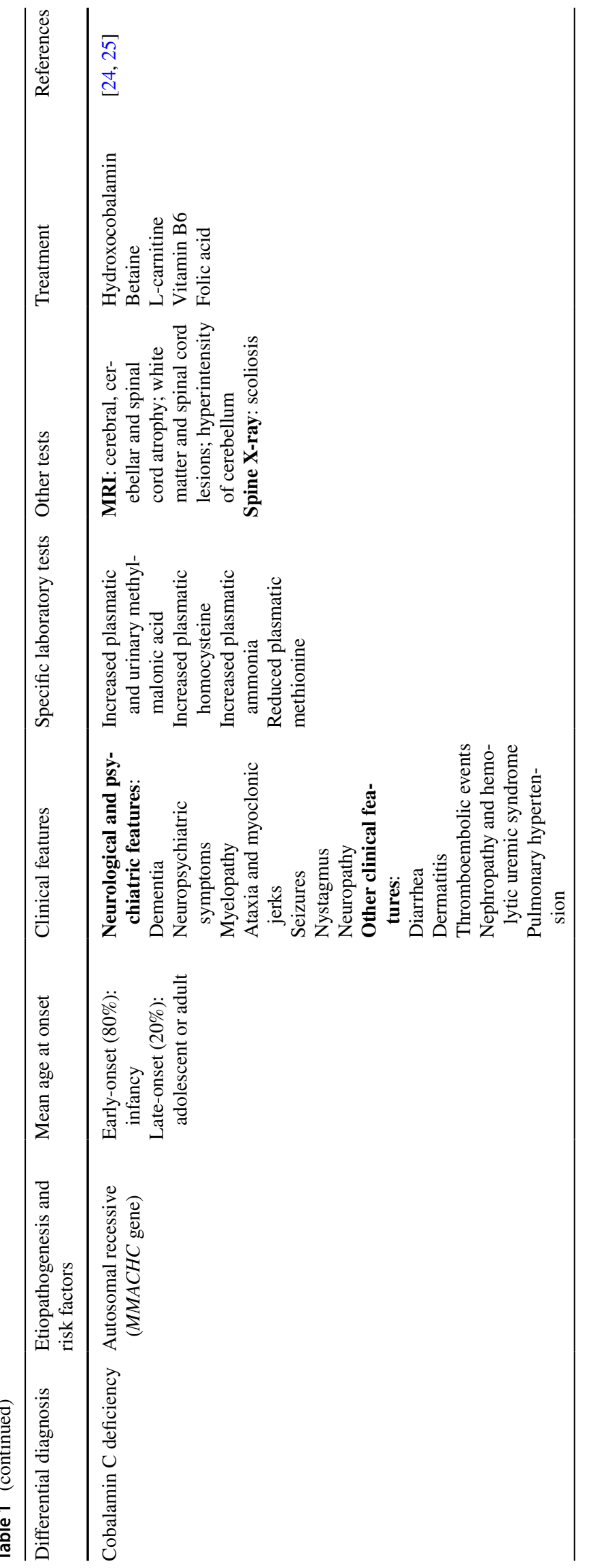

黑 Springer 


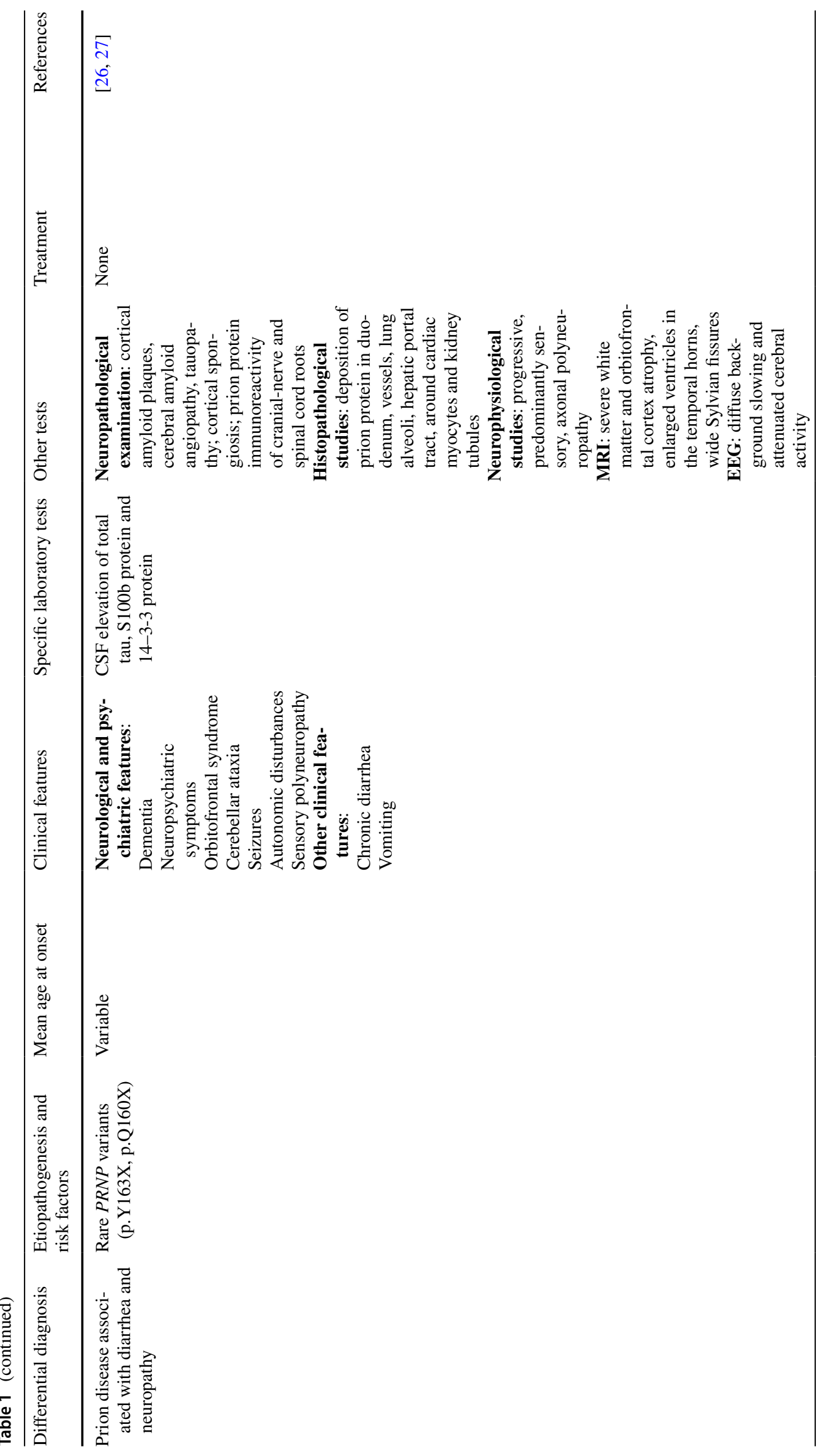




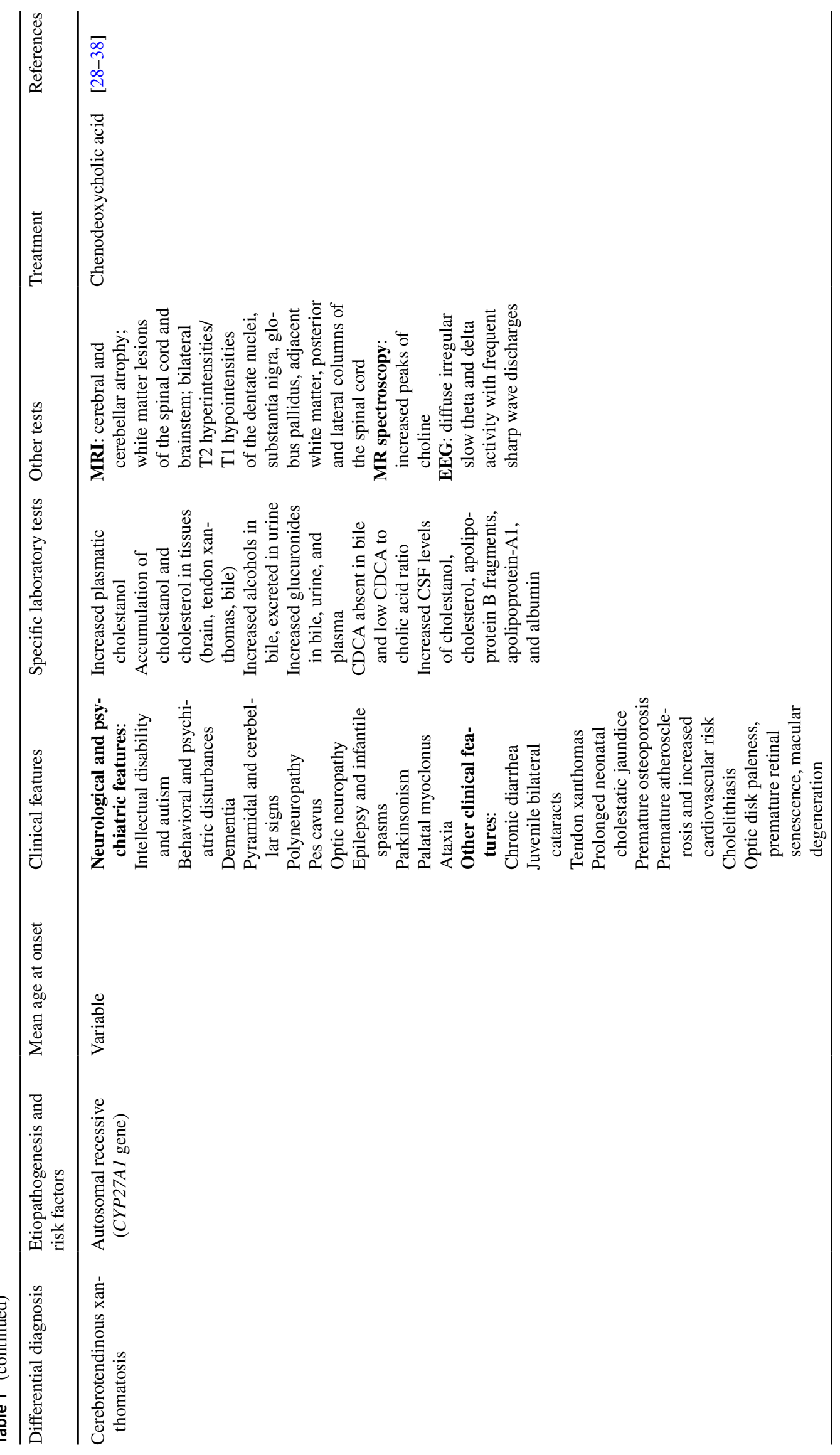




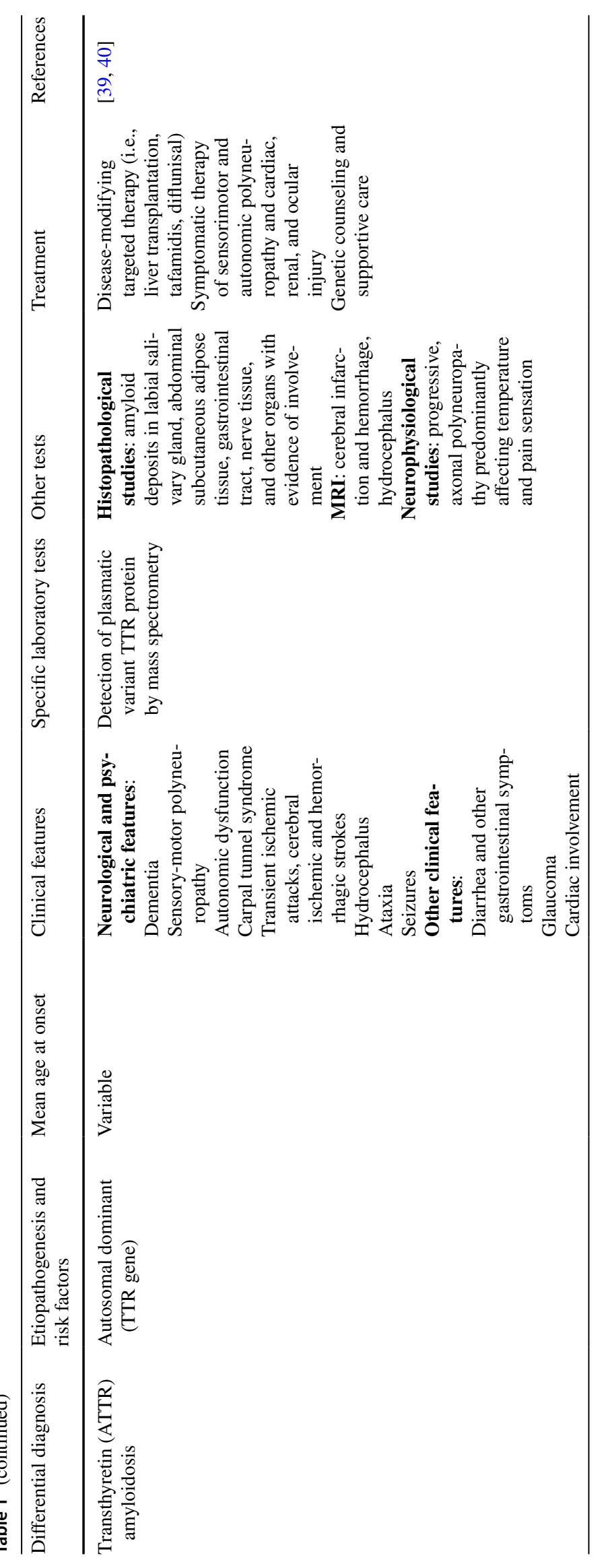




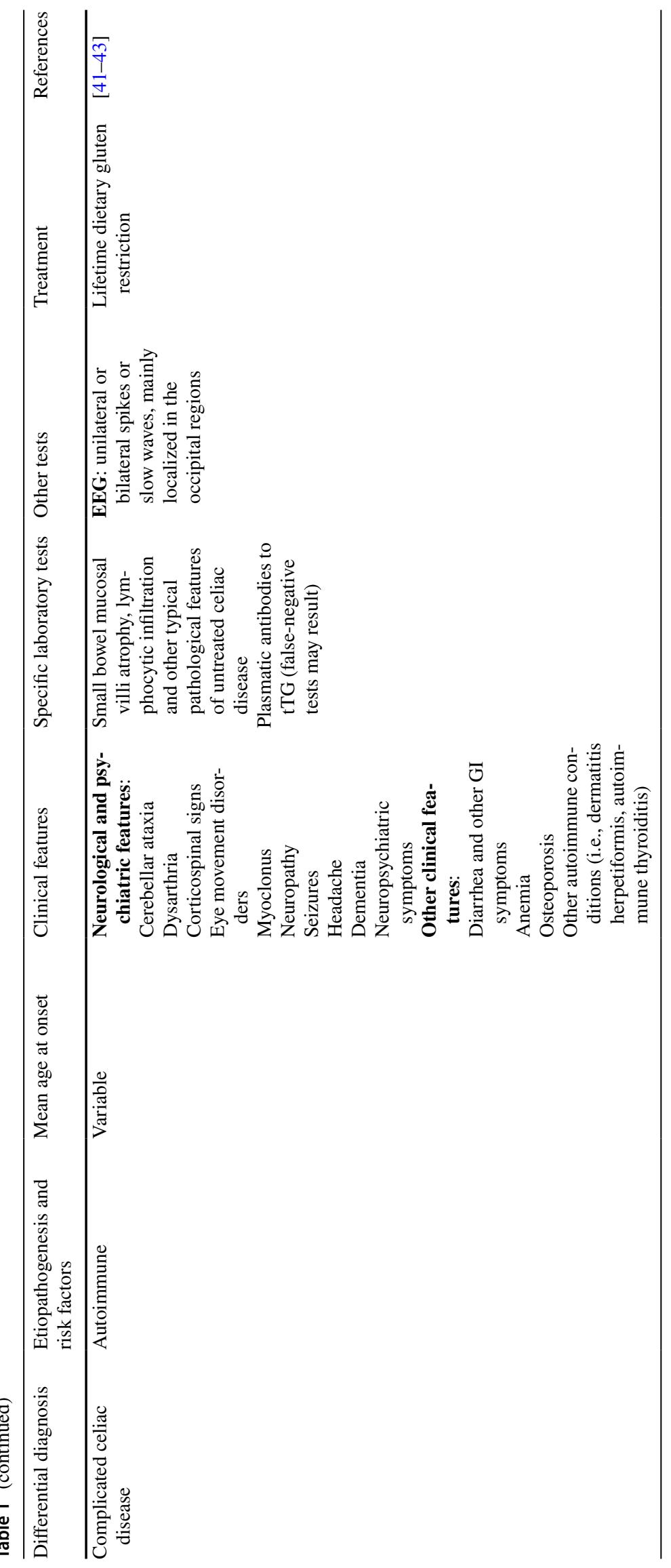

包 Springer 
A cerebral magnetic resonance imaging (MRI) showed diffuse cortical atrophy and lateral ventricles dilatation, more prominent on the right, in addition to signs of the previous traumatic hemorrhage and ischemic stroke (Fig. 1c-d). Serial electroencephalograms (EEG) showed a progressive worsening of diffuse encephalopathy, with symmetric cortical electrical activity attenuation and increased slow activity.

As unexplained diarrhea persisted, digestive endoscopy was repeated, confirming a granular aspect of intestinal lining. PAS staining and PCR of T. whipplei on duodenal biopsies resulted negative.

An extended empiric antimicrobial therapy was initiated since an undetected infectious etiology could not be excluded, firstly with piperacillin/tazobactam and subsequently with meropenem without clinical benefit. Even though an autoimmune origin of the disorder did not seem probable, a therapeutic attempt with intravenous steroid bolus (methylprednisolone $500 \mathrm{mg} /$ day) was started and stopped after 3 days, because of severe worsening of symptoms. The clinical picture deterioration after steroids appeared to discredit the hypothesis of an autoimmune encephalitis (i.e., anti-DPPX encephalitis).

As cognitive decline progressed, a lumbar puncture was performed, and cerebrospinal fluid (CSF) analysis displayed normal cell count $\left(<2\right.$ cells $/ \mathrm{mm}^{3}$; normal value: $<5$ cells $/ \mathrm{mm}^{3}$ ), glucose at lower level of normal range $(42 \mathrm{mg} /$ $\mathrm{dL}$; normal value: $>40 \mathrm{mg} / \mathrm{dL}$ ), and high proteins level (1318 mg/L; normal value: $150-400 \mathrm{mg} / \mathrm{L})$. Molecular tests aimed to amplify EBV-DNA, HSV1/2-DNA, CMV-DNA, VZV-DNA, enterovirus-RNA, and polyomavirus-JC-DNA were negative. 14.3.3 protein was negative. Given the presence of persistent diarrhea, ophthalmoparesis, and rapidly progressive cognitive impairment, a suspicion of WD was advanced, and PCR assay for T. Whipplei was performed on CSF, which was positive. Appropriate therapy was then started with ceftriaxone ( $2 \mathrm{~g}$ twice a day) for 2 weeks, followed by cotrimoxazole (160/800 mg twice a day). Shortly after the start of specific antimicrobial therapy, a recovery of neurological deficits initiated; alertness, gaze, and speech were greatly improved in about a week. Physiotherapy could be started, and the patient was transferred to the Rehabilitation Unit by the end of December.

The patient was then seen again when the period of lockdown due to COVID-19 pandemic ended. At the first outpatient visit (in November 2020, 8 months after discharge), he was alert and oriented times three. His speech was fluent and correct, and he followed multistep commands. Even though complete neuropsychological testing was not performed, cognitive improvement was remarkable. At visual fields examination, the patient showed extinction of left stimulus on double simultaneous stimulation. Conjugate right gaze was limited, right-beating nystagmus appeared on left gaze and gaze impersistence was noticed. Vertical gaze was preserved. Left hemiparesis including central facial palsy and increased spastic tone of both left arm and leg were remarkably reduced. The patient was able to walk with only a single side support. The remaining neurological examination was normal. Brain MRI performed in October 2020 was unchanged. At the last follow-up in April 2021, arousal, speech, and cognition were normal. The patient was now able to live independently, to walk without any support in and outdoor. Even if with a slightly reduced dexterity, he regained the ability to play the violin even in the orchestra, and to perform in public concerts. Neurological examination was further improved, as the patient showed only neglect of left extrapersonal space, nystagmus on bilateral gaze (more pronounced on the right), and left spastic hemiparetic gait. The patient is currently continuing antibiotic therapy.

\section{Systematic literature review}

Figure 2 shows the PRISMA flow diagram. Out of 889 records detected by the search strategy, 202 were removed as duplicates. Titles and abstracts of the remaining 687 papers were screened. We excluded articles not written in English $(n=101)$ and not consistent with the aim of the review $(n=279)$. We considered 307 full-text articles for eligibility, and 193 were excluded (Fig. 2). Finally, we reviewed 114 papers (98 case reports, 16 case series) for a total of 147 patients. The complete list of publications included in the systematic review is reported in Supplementary Table 1.

\section{Demographic characteristics}

In 2 and 1 out of 147 patients identified through literature search, age at onset and gender were respectively not reported. For the remaining subjects, mean age at onset was 51.1 years (DS 11.7) and 78.8\% patients were males.

\section{Neurological features and accuracy of CNS WD diagnosis}

According to Louis et al.'s criteria [10], a "definite" diagnosis of CNS WD was made in 143/147 patients (97.3\%). In the remaining cases, the diagnosis was "possible."

Most $(142 / 147,96.6 \%)$ of the patients had other neurological signs or symptoms in addition to cognitive decline. The most common neurological features reported included psychological and behavioral alterations $(52.4 \%)$, supranuclear ophthalmoplegia (41.5\%), hypothalamic involvement (38.1\%), and disorders of consciousness (36.7\%).

The pathognomonic oculomasticatory myorhythmia and oculo-facial-skeletal myorhythmia were found only in $34 / 147$ (23.1\%) patients. Myoclonus, which is considered part of the classic triad of neurological features of CNS WD, was detected in 28/147 (19.0\%) patients. 


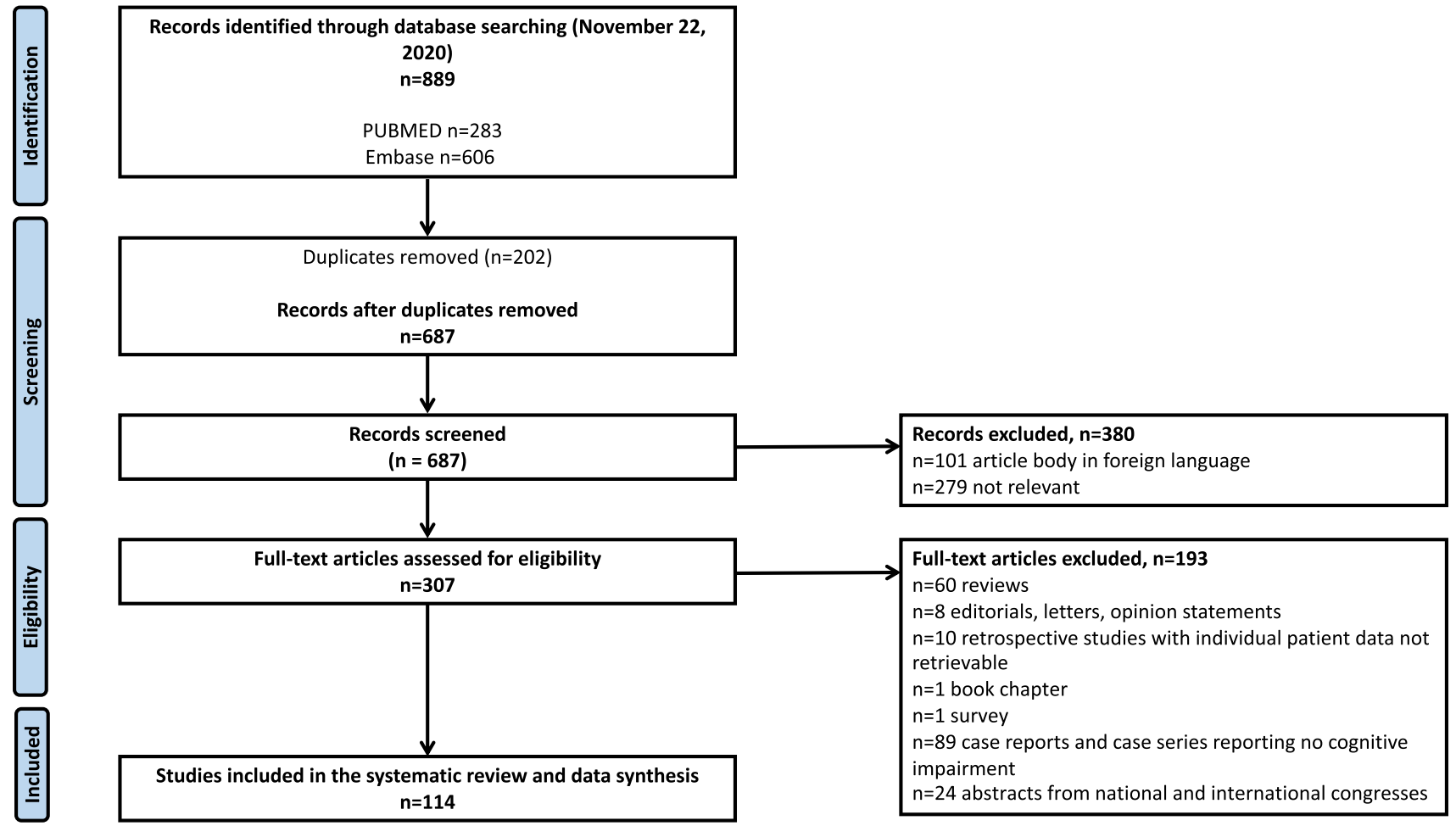

Fig. 2 PRISMA flow diagram

Neurological signs and symptoms are summarized in Table 2.

\section{Non-neurological features}

Table 3 summarizes non-neurological features found in patients with WD and cognitive impairment.

Among gastrointestinal symptoms, 65/147 (44.2\%) patients presented weight loss, and 53/147 (36.1\%) developed diarrhea. In decreasing order of frequency, abdominal pain (14.3\%), nausea (4.8\%), and vomit (4.1\%) were described.

Common systemic features included arthralgia and/ or arthritis (41.5\%) and fever (38.1\%). Lymphadenopathy $(18.4 \%)$, anorexia $(15.6 \%)$, skin alterations $(12.2 \%)$, and fatigue $(6.8 \%)$ were reported less frequently. A reduced number of patients showed signs and symptoms involving different organs and apparatus, mainly respiratory, cardiac, endocrinological, and ocular.

\section{Neuroimaging}

In the reviewed literature, a wide spectrum of neuroimaging abnormalities, mostly nonspecific, were reported. CT and MRI images were normal in 15 out of $141(10.6 \%)$ cases in which neuroimaging features were reported.
In 19/141 (13.5\%) cases, a single brain lesion was described, with a supratentorial localization in $15 / 16$ (93.8\%) cases, and an infratentorial one in 1/16 (6.3\%). In 3 cases, the location of the single brain lesion was not reported. Out of the reviewed cases reporting a single brain lesion, the imaging investigation showed a pseudotumoral mass in 3/19 (15.8\%) and post-gadolinium enhancement in $6 / 19(31.6 \%)$.

Neuroimaging techniques showed multifocal brain lesions in 79/141 (56.0\%) cases, whose localization was reported as only supratentorial in 41/77 (53.2\%), only infratentorial in $4 / 77$ (5.2\%), and both supra-infratentorial in 32/77 (41.6\%) cases. In 2 patients, the localization was not specified. Gadolinium enhancement was present in 33/79 (41.2\%) cases. When observed (14/141, 9.9\%), hydrocephalus was obstructive in $3 / 14(21.4 \%)$ and associated with normal pressure in $11 / 14(78.6 \%)$ cases.

Brain imaging showed cortical and/or subcortical atrophy in 36/141 (25.6\%), diffuse cerebral edema in 2/141 (1.4\%), ependymal lesions in $3 / 141$ (2.1\%), and intracerebral hemorrhage in $2 / 141(1.4 \%)$ cases.

Meningeal involvement was reported in 4/141 (2.8\%) cases, consisting of diffuse increased contrast enhancement in 2, diffusely increased thickness of meningeal layers in 1, and meningeal infiltrates in 1 case.

Spinal cord involvement was reported in 2/141 (1.4\%) cases, both of which as a single lesion. 
Table 2 Neurological features in patients with WD and cognitive impairment

\begin{tabular}{ll}
\hline Sign and/or symptom & $\mathrm{N}^{\circ}$ of cases (\%) \\
\hline Psychological and behavioral alterations & $77(52.4 \%)$ \\
Supranuclear ophthalmoplegia & $61(41.5 \%)$ \\
Hypothalamic involvement & $56(38.1 \%)$ \\
Disorders of consciousness & $54(36.7 \%)$ \\
Dizziness AND/OR postural instability AND/OR alterations of gait & $46(31.3 \%)$ \\
Cerebellar features & $39(26.5 \%)$ \\
Oculomasticatory myorhythmia (OMM) AND/OR oculo-facial-skeletal myorhythmia & $34(23.1 \%)$ \\
(OFSM) & \\
Cranial nerves involvement & $34(23.1 \%)$ \\
Dysphagia AND/OR dysarthria & $34(23.1 \%)$ \\
Extrapyramidal signs AND/OR involuntary movements & $31(21.1 \%)$ \\
Seizures & $29(19.7 \%)$ \\
Pyramidal signs & $29(19.7 \%)$ \\
Myoclonus & $28(19.0 \%)$ \\
Eye movement disorders NOT ophthalmoplegia & $23(15.6 \%)$ \\
Autonomic dysfunction & $21(14.3 \%)$ \\
Headache & $19(12.9 \%)$ \\
Symptoms and signs not otherwise classifiable & $14(9.5 \%)$ \\
Sensory abnormalities & $7(4.8 \%)$ \\
Meningo-encephalitis & $6(4.1 \%)$ \\
Neuropathy & $6(4.1 \%)$ \\
Myelopathy & $2(1.4 \%)$ \\
Myopathy AND/OR muscular dystrophy & $2(1.4 \%)$ \\
\hline
\end{tabular}

Table 4 summarizes brain imaging findings of the cases included in the systematic review.

\section{CSF examination}

CSF routine examination disclosed nonspecific results. Cell count was reported in 106 cases, showing mild-to-moderate pleocytosis in $53.8 \%$ of them (57/106).

CSF protein levels were almost equally divided between normal (46/94, 48.9\%) and increased (45/94, 47.9\%), with only a few reports showing reduced levels $(3 / 94,3.2 \%)$.

In most of the cases that reported CSF glucose level, this was normal $(68 / 75,90.7 \%)$. In $3 / 75$ cases, glucose level was increased $(4.0 \%)$ and in 4/75 reduced (5.3\%).

The result of PCR assay against $T$. whipplei was reported in $35 / 153(22.9 \%)$ of the reviewed cases, resulting positive in 24 of them $(68.6 \%)$. In other 5 cases, analysis of CSF showed the presence of $T$. whipplei with other techniques, including electronic microscopy (2 cases) and PAS-positive stain (3 cases) (Table 5).

\section{Discussion}

WD is an infectious, systemic, chronic, and often relapsing disease. It represents one of the greatest mimickers of medicine, as it can present with a broad range of signs and symptoms which often lead to misdiagnosis. Neurological involvement is frequent and is usually combined with systemic features. Notably, cognitive decline is by far the most typical CNS manifestation [44, 45].

This systematic review provides epidemiological, clinical, neuroimaging, and laboratory details of cognitive impairment in WD. A quite large number of cases was included for qualitative analysis. Data collected show a predominance of male patients. Psychological and behavioral disturbances, including mood disorders and apathy, accompany cognitive changes in half of the patients with WD. In decreasing order of frequency, supranuclear ophthalmoplegia, hypothalamic involvement, and disorders of consciousness are described. In comparison 
Table 3 Non-neurological features in patients with WD and cognitive impairment
Sign and/or symptom

$\mathrm{N}^{\circ}$ of cases (\%)

Gastrointestinal signs and symptoms

Weight loss

$65(44.2 \%)$

Diarrhea

$53(36.1 \%)$

Abdominal pain

$21(14.3 \%)$

Nausea

$7(4.8 \%)$

Vomit

$6(4.1 \%)$

Gastroenteritis

$5(3.4 \%)$

Gastrointestinal bleeding (i.e., hematochezia, hematemesis)

$3(2.0 \%)$

Constipation

$2(1.4 \%)$

Obesity

$2(1.4 \%)$

$2(1.4 \%)$

Systemic signs and symptoms

Arthralgia/arthritis

$61(41.5 \%)$

Fever

$56(38.1 \%)$

Lymphadenopathy

$27(18.4 \%)$

Anorexia

$23(15.6 \%)$

Skin pigmentation/alterations

$18(12.2 \%)$

Fatigue

$10(6.8 \%)$

Sweating

$6(4.1 \%)$

Blood cells cytopenia (i.e., anemia, pancytopenia)

$6(4.1 \%)$

Hepatosplenomegaly AND/OR hepatitis AND/OR cholestasis

$6(4.1 \%)$

Peripheral edema

$4(2.7 \%)$

Syncope

$3(2.0 \%)$

$1(0.7 \%)$

\section{Respiratory signs and symptoms}

Pneumonia/bronchopneumonia

$6(4.1 \%)$

Dyspnea

$4(2.7 \%)$

Obstructive sleep apnea

$3(2.0 \%)$

Pleuritic chest pain

$3(2.0 \%)$

Pleural effusion

$2(1.4 \%)$

Cardiac signs and symptoms

Cardiac valve alterations

$10(6.8 \%)$

Pericarditis

$4(2.7 \%)$

Congestive heart failure

$3(2.0 \%)$

Cardiac hypokinesia/akinesia

$2(1.4 \%)$

Cardiomegaly

$1(0.7 \%)$

Endocrinological alterations NOT hypothalamic

Hypogonadism

$3(2.0 \%)$

Diabetes mellitus

$1(0.7 \%)$

Ocular signs and symptoms

Uveitis

$5(3.4 \%)$

Blurred vision

$4(2.7 \%)$

Keratitis

$3(2.0 \%)$

Retinal alterations (i.e., hemorrhage, retinitis)

$3(2.0 \%)$

Conjunctivitis

$2(1.4 \%)$

$1(0.7 \%)$

$1(0.7 \%)$ 
Table 4 Neuroimaging features in patients with WD and cognitive impairment

\begin{tabular}{ll}
\hline Neuroimaging features & $\mathrm{N}^{\circ}$ of cases (\%) \\
\hline Normal & $15(10.6 \%)$ \\
Single cerebral or cerebellar lesion & $19(13.5 \%)$ \\
Pseudotumoral mass & $3(15.8 \%)$ \\
Post-gadolinium enhancement & $6(31.6 \%)$ \\
Localization & \\
$\quad$ Supratentorial & $15(93.8 \%)$ \\
$\quad$ Infratentorial & $1(6.3 \%)$ \\
Multifocal cerebral and/or cerebellar lesions & $79(56.0 \%)$ \\
Post-gadolinium enhancement & $33(41.8 \%)$ \\
Localization & \\
Supratentorial & $41(53.2 \%)$ \\
Infratentorial & $4(5.2 \%)$ \\
Both & $32(41.6 \%)$ \\
Diffuse cerebral edema & $2(1.4 \%)$ \\
Cortical and/or subcortical atrophy & $36(25.4 \%)$ \\
Hydrocephalus & $14(9.9 \%)$ \\
Obstructive & $3(21.4 \%)$ \\
Normal pressure & $11(78.6 \%)$ \\
Ependymal lesions & $3(2.1 \%)$ \\
Intracerebral hemorrhage & $2(1.4 \%)$ \\
Single spinal cord lesion & $2(1.4 \%)$ \\
Meningeal involvement & $4(2.8 \%)$ \\
\hline
\end{tabular}

Table 5 Cerebrospinal fluid examination in patients with WD and cognitive impairment

\begin{tabular}{ll}
\hline CSF examination & $\mathrm{N}^{\circ}$ of cases $(\%)$ \\
\hline Cell count & 106 \\
Normal & $49(46.2 \%)$ \\
Increased & $57(53.8 \%)$ \\
Protein level & 94 \\
Normal & $46(48.9 \%)$ \\
Increased & $45(47.9 \%)$ \\
Reduced & $3(3.2 \%)$ \\
Glucose level & 75 \\
Normal & $68(90.7 \%)$ \\
Increased & $3(4.0 \%)$ \\
Reduced & $4(5.3 \%)$ \\
T. Whipplei PCR & 35 \\
Positive & $24(68.6 \%)$ \\
Negative & $11(31.4 \%)$ \\
\hline
\end{tabular}

with a recent systematic review of movement disorders and oculomotor abnormalities in WD [45], hypothalamic involvement detection rate was higher in our systematic review (38\% vs 19\%). Two are the possible explanations of this inconsistency: first, we included a larger number of cases as we considered all patients with WD and cognitive impairment, which represents the most frequent neurological manifestation of WD; second, we included sleep disturbances under the category "hypothalamic involvement," while sleep disorders were listed separately from hypothalamic dysfunction by Bally et al. [45]. Consistent with previous works on different cohorts [45], oculomasticatory myorhythmia and oculo-facial-skeletal myorhythmia were reported in almost one quarter of patients with WD and CNS involvement. As a consequence, oculomasticatory myorhythmia and oculo-facial-skeletal myorhythmia, which are considered pathognomonic for CNS WD [46, 47], are actually found only in a minority of patients with WD and neurological involvement.

A previous review of CNS WD [48] showed that no pathognomonic neuroimaging pattern is associated with CNS WD. Our systematic review confirms that the most common brain imaging finding is represented by $\mathrm{T} 2$-weighted hyperintensities, with post-gadolinium enhancement in a significant number of cases. In some patients, brain imaging exhibits atypical patterns, which include pseudotumoral masses [49], cerebral hemorrhages [50], ependymal involvement [51], and spinal cord lesions [52].

A 12-year retrospective study of PCR WD diagnoses in an infectious reference center [53] showed that the number of patients tested for T. Whipplei had significantly increased in the period 2000-2012. Among the 27,923 samples analyzed, 2185 were CSF and a diagnosis was reached in $3.3 \%$ cases. In our systematic review, we showed that $T$. Whipplei PCR had been performed on CSF only in one-fourth of cases. In the remaining cases, CNS WD diagnosis was reached through electronic microscopy or PAS-positive stain on CSF or by the association of a positive T. Whipplei PCR result obtained on a different specimen (i.e., duodenum biopsy) and typical neurological symptoms.

Although cognitive deterioration is the most frequent neurological manifestation in WD, its neuropsychological pattern is not known. Recently, Knast et al. [54] performed a neuropsychological evaluation of a patient with WD and cognitive dysfunction. Concentration, verbal, and auditory learning; remembering and recognition; and verbal fluency represented the most impaired cognitive domains. Previously, Manzel et al. [55] performed serial neuropsychological assessments of a patient with CNS WD, who showed deficits in orientation to time and personal information, sustained attention, constructional praxis, speed of information processing, and executive function. Unfortunately, we did not have the opportunity to perform an extensive cognitive evaluation because the clinical picture of the patient rapidly deteriorated after admission, with severe consciousness disturbances. 
The patient described in our case report had a history of autoimmune MPGN, associated with reduction in C3 and C4 fractions, had undergone several immunosuppressive therapies, and showed IgG antibodies deficit and a reduced number of lymphocytes T CD3 + (both CD4 + and CD8 +) and B CD19 + during hospitalization. The role of immune deficits in WD is controversial. Even though most patients with WD do not usually present a history of immunosuppression and opportunistic infections, some immunological host factors, including defective lymphocytes T helper 1 response $[4,56]$ and monocyte/macrophage impairment [57], play a role in increasing susceptibility to WD.

\section{Conclusions}

Our review confirms the high frequency of cognitive decline as a neurological feature associated with WD and highlights CNS WD heterogeneity in terms of clinical picture, neuroimaging, and CSF findings. In this scenario, the clinical suspicion is pivotal to guide correct diagnostic strategies aimed to initiate the proper antimicrobial therapy as soon as possible, to limit and possibly revert the clinical deterioration.

Supplementary Information The online version contains supplementary material available at https://doi.org/10.1007/s10072-021-05844-5.

Author contribution All authors contributed to the study conception and design. AM and GQ: Material preparation, data collection, and analysis. AM, GQ, and CL: Writing of original draft. LP: Revision of original draft.

Data availability The datasets generated for this study will not be made publicly available. Nevertheless, further analyses might be available from authors by request to the corresponding author.

\section{Declarations}

Conflict of interest The authors declare no competing interests.

Statement of human and animal rights The study was performed in accordance with the principles of the Declaration of Helsinki.

Informed consent Informed consent was obtained from the patient.

\section{References}

1. Relman DA, Schmidt TM, MacDermott RP, Falkow S (1992) Identification of the uncultured Bacillus of Whipple's disease. N Engl J Med 327:293-301. https://doi.org/10.1056/NEJM199207 303270501

2. Morgan AD (1961) The first recorded case of Whipple's disease? Gut 2:370-372. https://doi.org/10.1136/gut.2.4.370

3. Whipple GH (1907) A hitherto undescribed disease characterized anatomically by deposits of fat and fatty acids in the intestinal and mesenteric lymphatic tissues. Bull Johns Hopkins Hosp 18:382-393

4. Moos V, Kunkel D, Marth T, Feurle GE, LaScola B, Ignatius R, Zeitz M, Schneider T (2006) Reduced peripheral and mucosal Tropheryma whipplei -specific Th1 response in patients with Whipple's disease. J Immunol 177:2015-2022. https://doi.org/ 10.4049/jimmunol.177.3.2015

5. Rolain J-M, Fenollar F, Raoult D (2007) False positive PCR detection of Tropheryma whipplei in the saliva of healthy people. BMC Microbiol 7:48. https://doi.org/10.1186/1471-2180-7-48

6. Martinetti M, Biagi F, Badulli C, Feurle GE, Müller C, Moos V, Schneider T, Marth T, Marchese A, Trotta L, Sachetto S, Pasi A, De Silvestri A, Salvaneschi L, Corazza GR (2009) The HLA alleles DRB1*13 and DQB1*06 are associated to Whipple's disease. Gastroenterology 136:2289-2294. https://doi.org/10.1053/j. gastro.2009.01.051

7. Arnold CA, Moreira RK, Lam-Himlin D, De Petris G, Montgomery E (2012) Whipple disease a century after the initial description. Am J Surg Pathol 36:1066-1073. https://doi.org/10.1097/ PAS.0b013e31825a2fa4

8. El-Abassi R, Soliman MY, Williams F, England JD (2017) Whipple's disease. J Neurol Sci 377:197-206. https://doi.org/10.1016/j. jns.2017.01.048

9. Schneider T, Moos V, Loddenkemper C, Marth T, Fenollar F, Raoult D (2008) Whipple's disease: new aspects of pathogenesis and treatment. Lancet Infect Dis 8:179-190. https://doi.org/10. 1016/S1473-3099(08)70042-2

10. Louis ED, Lynch T, Kaufmann P, Fahn S, Odel J (1996) Diagnostic guidelines in central nervous system Whipple's disease. Ann Neurol 40:561-568. https://doi.org/10.1002/ana.410400404

11. de Oliveira Alves A, Bortolato T, Bernardes Filho F (2018) Pellagra. J Emerg Med 54:238-240. https://doi.org/10.1016/j.jemer med.2017.10.010

12. Cao S, Wang X, Cestodio K (2019) Pellagra, an almost-forgotten differential diagnosis of chronic diarrhea: more prevalent than we think. Nutr Clin Pract 35:860-863. https://doi.org/10.1002/ncp. 10418

13. Oldham MA, Ivkovic A (2012) Pellagrous encephalopathy presenting as alcohol withdrawal delirium: a case series and literature review. Addict Sci Clin Pract 7:12. https://doi.org/10.1186/ 1940-0640-7-12

14. Vernau K, Napoli E, Wong S, Ross-Inta C, Cameron J, Bannasch D, Bollen A, Dickinson P, Giulivi C (2015) Thiamine deficiencymediated brain mitochondrial pathology in Alaskan Huskies with mutation in SLC19A3.1. Brain Pathol 25:441-453. https://doi.org/ 10.1111/bpa.12188

15. Shang W, Chen X, Li X, Chen H, Tang S, Hong H (2017) Epileptic seizures in nonalcoholic Wernicke's encephalopathy: a case report and literature review. Metab Brain Dis 32:2085-2093. https://doi.org/10.1007/s11011-017-0106-1

16. Nakamura ZM, Tatreau JR, Rosenstein DL, Park EM (2018) Clinical characteristics and outcomes associated with high-dose intravenous thiamine administration in patients with encephalopathy. Psychosomatics 59:379-387. https://doi.org/10.1016/j.psym.2018. 01.004

17. Gibson GE, Hirsch JA, Fonzetti P, Jordan BD, Cirio RT, Elder J (2016) Vitamin B1 (thiamine) and dementia. Ann N Y Acad Sci 1367:21-30. https://doi.org/10.1111/nyas.13031

18. Nishimoto A, Usery J, Winton JC, Twilla J (2017) High-dose parenteral thiamine in treatment of Wernicke's encephalopathy: case series and review of the literature. In Vivo (Brooklyn) 31:121-124. https://doi.org/10.21873/invivo.11034

19. Zhou Q, Zhu X, Meng H, Zhang M, Chen S (2020) Anti-dipeptidyl-peptidase-like protein 6 encephalitis, a rare cause of reversible rapid progressive dementia and insomnia. J Neuroimmunol 339:577114. https://doi.org/10.1016/j.jneuroim.2019.577114 
20. Boronat A, Gelfand JM, Gresa-Arribas N, Jeong HY, Walsh M, Roberts K, Martinez-Hernandez E, Rosenfeld MR, Balice-Gordon R, Graus F, Rudy B, Dalmau J (2013) Encephalitis and antibodies to dipeptidyl-peptidase-like protein- 6 , a subunit of $\mathrm{Kv} 4.2$ potassium channels. Ann Neurol 73:120-128. https://doi.org/10.1002/ ana. 23756

21. Heine J, Prüss H, Bartsch T, Ploner CJ, Paul F, Finke C (2015) Imaging of autoimmune encephalitis - relevance for clinical practice and hippocampal function. Neuroscience 309:68-83. https:// doi.org/10.1016/j.neuroscience.2015.05.037

22. Hara M, Ariño H, Petit-Pedrol M, Sabater L, Titulaer MJ, Martinez-Hernandez E, Schreurs MWJ, Rosenfeld MR, Graus F, Dalmau J (2017) DPPX antibody-associated encephalitis. Neurology 88:1340-1348. https://doi.org/10.1212/WNL.0000000000003796

23. Tobin WO, Lennon VA, Komorowski L, Probst C, Clardy SL, Aksamit AJ, Appendino JP, Lucchinetti CF, Matsumoto JY, Pittock SJ, Sandroni P, Tippmann-Peikert M, Wirrell EC, McKeon A (2014) DPPX potassium channel antibody: frequency, clinical accompaniments, and outcomes in 20 patients. Neurology 83:1797-1803. https://doi.org/10.1212/WNL.0000000000000991

24. Gilson RC, Wallis L, Yeh J, Gilson RT (2018) Dementia, diarrhea, desquamating shellac-like dermatitis revealing late-onset cobalamin C deficiency. JAAD Case Reports 4:91-94. https://doi.org/ 10.1016/j.jdcr.2017.09.016

25. Wang S, Yan C, Liu Y, Zhao Y (2018) Late-onset cobalamin C deficiency Chinese sibling patients with neuropsychiatric presentations. Metab Brain Dis 33:829-835. https://doi.org/10.1007/ s11011-018-0189-3

26. Mead S, Gandhi S, Beck J, Caine D, Gajulapalli D, Carswell C, Hyare H, Joiner S, Ayling H, Lashley T, Linehan JM, Al-Doujaily H, Sharps B, Revesz T, Sandberg MK, Reilly MM, Koltzenburg M, Forbes A, Rudge P, Brandner S, Warren JD, Wadsworth JDF, Wood NW, Holton JL, Collinge J (2013) A novel prion disease associated with diarrhea and autonomic neuropathy. N Engl J Med 369:1904-1914. https://doi.org/10.1056/NEJMoa1214747

27. Fong JC, Rojas JC, Bang J, Legati A, Rankin KP, Forner S, Miller ZA, Karydas AM, Coppola G, Grouse CK, Ralph J, Miller BL, Geschwind MD (2016) Genetic Prion Disease Caused by PRNP Q160X mutation presenting with an orbitofrontal syndrome, cyclic diarrhea, and peripheral neuropathy. J Alzheimer's Dis 55:249-258. https://doi.org/10.3233/JAD-160300

28. Mignarri A, Gallus GN, Dotti MT, Federico A (2014) A suspicion index for early diagnosis and treatment of cerebrotendinous xanthomatosis. J Inherit Metab Dis 37:421-429. https://doi.org/ 10.1007/s10545-013-9674-3

29. Verrips A, Hoefsloot LH, Steenbergen GCH, Theelen JP, Wevers RA, Gabreëls FJM, van Engelen BGM, van den Heuvel LPWJ (2000) Clinical and molecular genetic characteristics of patients with cerebrotendinous xanthomatosis. Brain 123:908-919. https:// doi.org/10.1093/brain/123.5.908

30. Degos B, Nadjar Y, del Amador MM, Lamari F, Sedel F, Roze E, Couvert P, Mochel F (2016) Natural history of cerebrotendinous xanthomatosis: a paediatric disease diagnosed in adulthood. Orphanet J Rare Dis 11:41. https://doi.org/10.1186/ s13023-016-0419-x

31. von Bahr S, Björkhem I, Van'tHooft F, Alvelius G, Nemeth A, Sjövall J, Fischler B (2005) Mutation in the sterol 27-hydroxylase gene associated with fatal cholestasis in infancy. J Pediatr Gastroenterol Nutr 40:481-486. https://doi.org/10.1097/01.MPG.00001 50419.23031.2A

32. Salen G, Steiner RD (2017) Epidemiology, diagnosis, and treatment of cerebrotendinous xanthomatosis (CTX). J Inherit Metab Dis 40:771-781. https://doi.org/10.1007/s10545-017-0093-8

33. Ly H, Bertorini TE, Shah N (2014) An adult male with progressive spastic paraparesis and gait instability. J Clin Neuromuscul Dis 16:98-103. https://doi.org/10.1097/CND.0000000000000058
34. Valdivielso P, Calandra S, Duran JC, Garuti R, Herrera E, Gonzalez P (2004) Coronary heart disease in a patient with cerebrotendinous xanthomatosis. J Intern Med 255:680-683. https://doi. org/10.1111/j.1365-2796.2004.01316.x

35. Dotti MT, Rufa A, Federico A (2001) Cerebrotendinous xanthomatosis: heterogeneity of clinical phenotype with evidence of previously undescribed ophthalmological findings. J Inherit Metab Dis 24:696-706. https://doi.org/10.1023/A:1012981019336

36. Kawabata M, Kuriyama M, Mori S, Sakashita I, Osame M (1998) Pulmonary manifestations in cerebrotendinous xanthomatosis. Intern Med 37:922-926. https://doi.org/10.2169/internalmedicine. 37.922

37. Fraidakis MJ (2013) Psychiatric manifestations in cerebrotendinous xanthomatosis, Transl. Psychiatry 3:e302-e302. https://doi. org/10.1038/tp.2013.76

38. Vaz FM, Ferdinandusse S (2017) Bile acid analysis in human disorders of bile acid biosynthesis. Mol Aspects Med 56:10-24. https://doi.org/10.1016/j.mam.2017.03.003

39. Sekijima Y (2015) Transthyretin (ATTR) amyloidosis: clinical spectrum, molecular pathogenesis and disease-modifying treatments. J Neurol Neurosurg Psychiatry 86:1036-1043. https://doi. org/10.1136/jnnp-2014-308724

40. Sekijima Y, Ueda M, Koike H, Misawa S, Ishii T, Ando Y (2018) Diagnosis and management of transthyretin familial amyloid polyneuropathy in Japan: red-flag symptom clusters and treatment algorithm. Orphanet J Rare Dis 13:6. https://doi.org/10.1186/ s13023-017-0726-x

41. M. Pennisi, A. Bramanti, M. Cantone, G. Pennisi, R. Bella, G. Lanza, Neurophysiology of the "Celiac Brain": Disentangling Gut-Brain Connections, Front. Neurosci. 11 (2017). https://doi. org/10.3389/fnins.2017.00498.

42. S. Yoosuf, G.K. Makharia, Evolving Therapy for Celiac Disease, Front. Pediatr. 7 (2019). https://doi.org/10.3389/fped.2019.00193.

43. Ciccocioppo R, Kruzliak P, Cangemi G, Pohanka M, Betti E, Lauret E, Rodrigo L (2015) The spectrum of differences between childhood and adulthood celiac disease. Nutrients 7:8733-8751. https://doi.org/10.3390/nu7105426

44. Compain C, Sacre K, Puéchal X, Klein I, Vital-Durand D, Houeto J-L, De Broucker T, Raoult D, Papo T (2013) Central nervous system involvement in Whipple disease. Medicine (Baltimore) 92:324-330. https://doi.org/10.1097/MD.0000000000000010

45. Bally JF, Méneret A, Roze E, Anderson M, Grabli D, Lang AE (2018) Systematic review of movement disorders and oculomotor abnormalities in Whipple's disease. Mov Disord 33:1700-1711. https://doi.org/10.1002/mds.27419

46. Revilla FJ, de la Cruz R, Khardori N, Espay AJ (2008) Teaching neuroimage: oculomasticatory myorhythmia: pathognomonic phenomenology of Whipple disease. Neurology 70:e25-e25. https:// doi.org/10.1212/01.wnl.0000287142.16160.0f

47. Schwartz MA, Selhorst JB, Ochs AL, Beck RW, Campbell WW, Harris JK, Waters B, Velasco ME (1986) Oculomasticatory myorhythrma: a unique movement disorder occurring in Whipple's disease. Ann Neurol 20:677-683. https://doi.org/10.1002/ana. 410200605

48. Black DF, Aksamit AJ, Morris JM (2010) MR imaging of central nervous system Whipple disease: a 15-year review. Am J Neuroradiol 31:1493-1497. https://doi.org/10.3174/ajnr.A2089

49. H. Malikova, J. Peregrin, Primary Whipple disease of the brain: case report with long-term clinical and MRI follow-up, Neuropsychiatr. Dis. Treat. (2015) 2461. https://doi.org/10.2147/NDT. S92066.

50. Wu L, Wang X, Wei H, Li C, Jia J (2008) Diffuse cortical lesions with hemorrhage in cerebral Whipple's disease. Clin Neurol Neurosurg 110:83-87. https://doi.org/10.1016/j.clineuro.2007.08.017

51. Vural A, Acar NP, Soylemezoglu F, Oguz KK, Dericioğlu N, Saka E (2015) Isolated central nervous system Whipple's disease: 
two cases. Clin Neurol Neurosurg 139:91-94. https://doi.org/10. 1016/j.clineuro.2015.08.028

52. Benito-León J, Arpa J, Louis ED, Herrera I, De La Loma A (2007) Isolated CNS Whipple disease: acute onset and relapsing-remitting course. Scand J Infect Dis 39:623-625. https://doi.org/10. 1080/00365540601115953

53. Edouard S, Fenollar F, Raoult D (2012) The rise of Tropheryma whipplei: a 12-year retrospective study of PCR diagnoses in our reference center. J Clin Microbiol 50:3917-3920. https://doi.org/ 10.1128/JCM.01517-12

54. Knast K, Rudzińska M, Dymon I, Tabaka-Pradela J, Dudek D (2017) Neurological and neuropsychological complications in the course of chronic Whipple's disease - case report. Psychiatr Pol 51:953-961. https://doi.org/10.12740/PP/OnlineFirst/61131

55. Manzel K, Tranel D, Cooper G (2000) Cognitive and behavioral abnormalities in a case of central nervous system Whipple disease. Arch Neurol 57:399. https://doi.org/10.1001/archneur. 57.3.399

56. Marth T, Kleen N, Stallmach A, Ring S, Aziz S, Schmidt C, Strober W, Zeitz M, Schneider T (2002) Dysregulated peripheral and mucosal Th1/Th2 response in Whipple's disease. Gastroenterology 123:1468-1477. https://doi.org/10.1053/gast.2002.36583

57. Bjerknes R, Laerum OD, Ødegaard S (1985) Impaired bacterial degradation by monocytes and macrophages from a patient with treated Whipple's disease. Gastroenterology 89:1139-1146. https://doi.org/10.1016/0016-5085(85)90221-5

Publisher's note Springer Nature remains neutral with regard to jurisdictional claims in published maps and institutional affiliations. 